\title{
Studies on leaf nutrient status and seed yield of different pruning intensity treatments in Azadirachta indica A. Juss plantation at Tirunelveli district of Tamil Nadu, India
}

\section{P. Prabakaran* and K. Kumaran}

Department of Forest Biology and Tree Improvement, Forest College and Research Institute, TNAU, Mettupalayam 641301, Tamil Nadu, India

*Corresponding Author: pprabufcri@gmail.com

\begin{abstract}
The pruning experiment was carried out in 12 year old Azadirachta indica (Neem) plantation at Pathamadai village, Seranmadevi Taluk, Tirunelveli district, Tamil Nadu. The Neem trees were imposed with three pruning intensities (15\% pruning, 25 $\%$ pruning and $45 \%$ pruning) and control for enhancing the flowering and fruiting in neem. The total nitrogen $(2.351 \%)$, total phosphorus $(0.349 \%)$, total potassium $(0.214 \%)$, chlorophyll 'a' $\left(0.437 \mathrm{mg} \mathrm{g}^{-1}\right)$, chlorophyll 'b' $\left(0.677 \mathrm{mg} \mathrm{g}^{-1}\right)$ and total chlorophyll $\left(1.108 \mathrm{mg} \mathrm{g}^{-1}\right)$ were found superior in $\mathrm{T} 2(25 \%$ pruning) and the lowest leaf nutrient status in control. The maximum neem seed yield was exhibited in 25 per cent pruning with the seed yield of $3.80 \mathrm{~kg}$. and the minimum was recorded in control (1.58 kg). To conclude the study, the moderate pruning in Neem tree enhanced the nutrient status in leaf and fruit yield.
\end{abstract}

Keywords: Neem, Pruning, Leaf nutrient, Chlorophyll content, Seed yield.

\section{INTRODUCTION}

Pruning is a common technique in horticulture crops to expose sunlight for induces vegetative and reproductive growth (Sarkka \& Erikson, 2003). In general, pruning is to observe and control the plant growth to manipulate branch, flowers and fruits production in off-season or through year. Numerous analyst and their examinations have underlined the result of pruning on blossoming and its impacts on the ensuing natural product development and amount just as its quality (Calatayud et al., 2007). Periodic pruning of fruit trees always reduces yield, but enhances fruit quality. Pruning builds natural product size, since abundance bloom buds are evacuated and pruning empowers the development of new shoots with excellent blossom buds (Dhillon \& Thakur, 2014; Prasath et al., 2017).

Azadirachta indica A. Juss (Neem), a suitable species for wasteland and other afforestation programme planted extensively in Tamil Nadu by forest department, farmers and other agencies suffers from irregular bearing which results in poor seed yield.

It is documented by earlier workers that due to profuse flowering in Azadirachta indica, the fruit set was very poor, resulting in large scale abscission of flowers as well as fruits during various stages of development. Normally in Neem, large plantation have failed in flowering and fruiting and by keeping this in mind, the pruning intensities was carried out to study the nutrient status and seed yield.

\section{MATERIAL AND METHODS}

The study was carried out during 2017-2018 in the Pathamadai village, Seranmadevi Taluk, Tirunelveli district, Tamil Nadu, India $\left(8^{\circ} 38^{\prime} 27.71^{\prime \prime} \mathrm{N}, 77^{\circ} 35^{\prime} 57.52^{\prime \prime}\right.$ E). 12 year old Neem trees were selected for productivity enhancement of Neem seed yield through the treatment of canopy management. The soil type is red sandy loam soil, slightly alkaline and low in organic carbon status. Available nitrogen is low, whereas the available phosphorus was medium and highest available potassium content.

The experiment was initiated during September, 2017. The trees were chosen based on uniform crown shape and age. The dormant pruning treatments were performed on the entire tree and consist of unpruned control and increasing levels of dormant pruning (removing $15 \%, 25 \%$ or $45 \%$ of the fruiting branches). The leaf samples were taken for evaluation at different stages during new flush formation, flowering, fruit development and harvesting.

\section{Nutritional status}

The processed and ground leaf samples were analyzed for macronutrients using appropriate methodology as furnished in table 1 and expressed in percentage. 


\begin{tabular}{llll}
\multicolumn{2}{l}{ Table } & 1. Standard procedures followed for leaf nutrient analysis. & \\
\hline S.N. & Parameter & Method adopted & References \\
\hline 1 & Nitrogen & Microkjeldahl method & Humphries (1973) \\
2 & Phosphorus & Vanadomolybdate yellow color method & Jackson (1973) \\
3 & Potassium & Flame photometry & Piper (1973) \\
\hline
\end{tabular}

\section{Chlorophyll content}

The concentrations of chlorophyll ' $a$ ', chlorophyll ' $b$ ' and total chlorophyll were estimated in the 34 progenies after three months interval period by adopting the method of Yoshida et al. (1976) and expressed as mg per gram of fresh weight.

Matured young fresh leaf samples of $250 \mathrm{mg}$ were collected, washed in distilled water and then ground with $10 \mathrm{ml}$ of $80 \%$ acetone using pestle and mortar. The homogenate solution was centrifuged at $500 \mathrm{rpm}$ for 10 minutes. The supernatant was collected and the volume was made up to $25 \mathrm{ml}$ using $80 \%$ acetone. The optical density of the content was measured at 663 and $645 \mathrm{~nm}$ (Tanee \& Albert, 2013). Then chlorophyll 'a', chlorophyll 'b' and total chlorophyll content were calculated using the following formulae:

$$
\begin{aligned}
& \text { Chlorophyll a content }\left(\mathrm{mg} \mathrm{g}^{-1}\right)=\frac{12.7 \times \text { OD at } 663 \mathrm{~nm}-2.69 \times \text { OD at } 645 \mathrm{~nm} \times \mathrm{V}}{1000 \times \mathrm{W}} \\
& \text { Chlorophyll b content }\left(\mathrm{mg} \mathrm{g}^{-1}\right)=\frac{22.7 \times \text { OD at } 645 \mathrm{~nm}-4.68 \times \text { OD at } 663 \mathrm{~nm} \times \mathrm{V}}{1000 \times \mathrm{W}} \\
& \text { Total chlorophyll content }\left(\mathrm{mg} \mathrm{g}^{-1}\right)=(8.02 \times \text { OD at } 663)+(20.2 \times \text { OD at 645) }) \text { Df }
\end{aligned}
$$

Where, V= Volume made $(25 \mathrm{ml})$; W= Weight of fresh sample taken; Df= Dilute factor.

\section{Seed yield}

The fruit has harvest and extracted seed from each tree were weighted and expressed in $\mathrm{kg} \mathrm{tree}^{-1}$.

\section{Statistical analysis}

The experimental data were subjected to statistical analysis by ANOVA for analysis of randomized block design as described by Panse \& Sukhatme (1978).

\section{RESULTS}

\section{Effect of different pruning intensities on nutrient status}

The effect of different pruning intensities on selected Neem trees were analyzed for total nitrogen, total phosphorus and total potassium content at four stages namely new flush formation, flowering, fruit development and harvesting stage.

\section{Total nitrogen}

The effect of different pruning intensities on total nitrogen content at four growth stage was recorded maximum during flowering stage in $\mathrm{T}_{2}\left(25 \%\right.$ pruning) with the value of 2.839 per cent followed by $\mathrm{T}_{1}-15 \%$ pruning $(1.869 \%)$, $\mathrm{T}_{3}-$ $45 \%$ pruning $(1.721 \%)$ and minimum $(1.574 \%)$ in $\mathrm{T}_{4}$ (Control). The $\mathrm{T}_{2}(25 \%$ pruning) treatment recorded the highest total nitrogen content in new flush formation, flowering, fruit development and harvesting stage with the value of $1.964 \%, 2.839 \%, 1.393 \%$ and $1.112 \%$ respectively (Table 2). As growth progressed, total nitrogen content increased from new flush formation to flowering stage and gradually decreased from fruit development to harvesting stage, with significant variation between each other. Among the treatments, the mean total nitrogen content was the highest in $\mathrm{T}_{2}$ ( $25 \%$ pruning) with the value of $2.351 \%$ followed by $\mathrm{T}_{1}-15 \%$ pruning $(1.658 \%), \mathrm{T}_{3}-45 \%$ pruning $(1.444 \%)$ and the minimum $(1.376 \%)$ was recorded in $\mathrm{T}_{4}$ (Control).

Table 2. Effect of different pruning intensities on total nitrogen content in Azadirachta indica A. Juss leaves.

\begin{tabular}{lrrrrr}
\hline \multirow{2}{*}{ Treatment } & \multicolumn{5}{c}{ Total Nitrogen (\%) } \\
\cline { 2 - 6 } & New Flush Formation & Flowering & Fruit Development & Harvesting & Mean \\
\hline T1 & 1.606 & 1.869 & 1.648 & 1.509 & 1.658 \\
$\mathrm{~T} 2$ & 1.964 & 2.839 & 2.512 & 2.089 & 2.351 \\
$\mathrm{~T} 3$ & 1.374 & 1.721 & 1.393 & 1.287 & 1.444 \\
Control & 1.484 & 1.574 & 1.334 & 1.112 & 1.376 \\
\hline SED & $\mathbf{0 . 0 0 9}$ & $\mathbf{0 . 0 2 8}$ & $\mathbf{0 . 0 6 2}$ & $\mathbf{0 . 0 2 5}$ & \\
CD $(\mathbf{0 . 0 5})$ & $\mathbf{0 . 0 2 1}$ & $\mathbf{0 . 0 6 3}$ & $\mathbf{0 . 1 3 3}$ & $\mathbf{0 . 0 5 5}$ & \\
\hline
\end{tabular}

\section{Total phosphorus}

Total phosphorus content among the treatments, $\mathrm{T}_{2}$ (25\% pruning) was observed with the highest total phosphorus content in new flush formation stage, flowering and fruit development stages with the values of $0.275 \%, 0.379 \% \mathrm{t}$ and 
$0.438 \%$ respectively. In the fruit development stage, the maximum total phosphorus content $(0.438 \%)$ was recorded in $\mathrm{T}_{2}\left(25 \%\right.$ pruning). On the contrary, the lowest total phosphorus content $(0.189 \%)$ was observed in $\mathrm{T}_{4}(\mathrm{Control})$ at new flush formation stage (Table 3).

Table 3. Effect of different pruning intensities on total phosphorus content in Azadirachta indica A. Juss leaves.

\begin{tabular}{lrrrrr}
\hline \multirow{2}{*}{ Treatment } & \multicolumn{5}{c}{ Total Phosphorus (\%) } \\
\cline { 2 - 6 } & New Flush Formation & Flowering & Fruit Development & Harvesting & Mean \\
\hline T1 & 0.254 & 0.305 & 0.347 & 0.258 & 0.291 \\
T2 & 0.275 & 0.379 & 0.438 & 0.302 & 0.349 \\
T3 & 0.189 & 0.233 & 0.268 & 0.243 & 0.232 \\
Control & 0.184 & 0.222 & 0.347 & 0.234 & 0.248 \\
\hline SED & $\mathbf{0 . 0 0 1}$ & $\mathbf{0 . 0 0 4}$ & $\mathbf{0 . 0 0 3}$ & $\mathbf{0 . 0 0 1}$ \\
CD $(\mathbf{0 . 0 5})$ & $\mathbf{0 . 0 0 2}$ & $\mathbf{0 . 0 0 9}$ & $\mathbf{0 . 0 0 7}$ & $\mathbf{0 . 0 0 3}$ \\
\hline
\end{tabular}

\section{Total potassium}

The total potassium content observed was the highest $(0.272 \%)$ in $\mathrm{T}_{2}\left(25 \%\right.$ pruning) followed by $\mathrm{T}_{1}-15 \%$ pruning $(0.245 \%), \mathrm{T}_{3}-45 \%$ pruning $(0.221 \%)$ and lowest in $\mathrm{T}_{4}$ (Control) with the value of $0.165 \%$ at the flowering stage. Whereas, $\mathrm{T}_{4}$ (Control) treatment registered the lowest total potassium content in three growth stages with the values of $0.106 \%$ (New flush formation), $0.165 \%$ (Flowering) and $0.133 \%$ (fruit development) respectively (Table 4).

The overall observations helped to conclude that $\mathrm{T}_{2}\left(25 \%\right.$ pruning) and $\mathrm{T}_{1}(15 \%$ pruning) were found superior in nutrient status (total nitrogen, total phosphorus and total potassium) at four growth stages in Neem plantation. On contrary, the lowest nutrient status at four growth stages was recorded in $\mathrm{T}_{4}$ (Control).

Table 4. Effect of different pruning intensities on total potassium content in Azadirachta indica A. Juss leaves.

\begin{tabular}{|c|c|c|c|c|c|}
\hline \multirow[t]{2}{*}{ Treatment } & \multicolumn{5}{|c|}{ Total Potassium (\%) } \\
\hline & New Flush Formation & Flowering & Fruit Development & Harvesting & Mean \\
\hline $\mathrm{T} 1$ & 0.143 & 0.245 & 0.205 & 0.178 & 0.193 \\
\hline $\mathrm{T} 2$ & 0.177 & 0.272 & 0.215 & 0.190 & 0.214 \\
\hline $\mathrm{T} 3$ & 0.137 & 0.221 & 0.184 & 0.149 & 0.173 \\
\hline Control & 0.106 & 0.165 & 0.133 & 0.160 & 0.141 \\
\hline SED & 0.002 & 0.004 & 0.002 & 0.001 & \\
\hline CD (0.05) & 0.005 & 0.008 & 0.004 & 0.003 & \\
\hline
\end{tabular}

\section{Effect of different pruning intensities on chlorophyll content}

The effect of different pruning intensities on selected Neem trees were analysed for chlorophyll 'a', chlorophyll 'b'and total chlorophyll at four growth stages namely new flush formation, flowering, fruit development and harvesting stage (Fig. 1).

\section{Chlorophyll ' $a$ '}

The chlorophyll 'a' content was reported maximum at fruit development stage viz., T2 (25\% pruning) $0.668 \mathrm{mg} \mathrm{g}^{-1}$ followed by T1 (15\% pruning) 0.591 , T3 (45\% pruning) $0.501 \mathrm{mg} \mathrm{g}^{-1}$ and control $\left(0.433 \mathrm{mg} \mathrm{g}^{-1}\right)$. The control recorded the lowest chlorophyll 'a' content in new flush formation, flowering, fruit development and harvesting stages with the values

$0.124 \mathrm{mg} \mathrm{g}^{-1}, 0.237 \mathrm{mg} \mathrm{g}^{-1}, 0.433 \mathrm{mg} \mathrm{g}^{-1}$ and $0.222 \mathrm{mg} \mathrm{g}^{-1}$ respectively.

\section{Chlorophyll ' $b$ '}

The chlorophyll ' $b$ ' content was observed minimum in control with the value of $0.322 \mathrm{mg} \mathrm{g}^{-1}, 0.431 \mathrm{mg} \mathrm{g}^{-1}, 0.420$ $\mathrm{mg} \mathrm{g}^{-1}, 0.537 \mathrm{mg} \mathrm{g}^{-1}$ in new flush formation, flowering, fruit development and harvesting stage respectively. On the contrary, the maximum value recorded in $\mathrm{T}_{2}\left(25 \%\right.$ pruning) treatment at four growth stages $0.556 \mathrm{mg} \mathrm{g}^{-1}$ ( $\mathrm{New}_{\text {flush }}$ formation), $0.662 \mathrm{mg} \mathrm{g}^{-1}$ (flowering), $0.787 \mathrm{mg} \mathrm{g}^{-1}$ (fruit development) and $0.702 \mathrm{mg} \mathrm{g}^{-1}$ (Harvesting).

\section{Total chlorophyll}

The effect of different pruning intensities on total chlorophyll content was estimated at four growth stages are presented in figure 1. Among the different pruning intensities, total chlorophyll content was found superior $\left(1.287 \mathrm{mg} \mathrm{g}^{-}\right.$ ${ }^{1}$ ) in $\mathrm{T}_{1}$ (15\% pruning) at fruit development stage followed by $\mathrm{T}_{2}-25 \%$ pruning $\left(1.250 \mathrm{mg} \mathrm{g}^{-1}\right), \mathrm{T}_{3}-45 \%$ pruning $\left(1.215 \mathrm{mg} \mathrm{g}^{-1}\right)$ and the lowest in control with the value of $0.838 \mathrm{mg} \mathrm{g}^{-1}$. The lowest total chlorophyll content was found in control at new flush formation stage with the value of $0.537 \mathrm{mg} \mathrm{g}^{-1}$.

Resulting the effect of the pruning in chlorophyll content (Chlorophyll ' $a$ ', chlorophyll ' $b$ ' and total chlorophyll), $\mathrm{T}_{2}$ (25\% pruning) and $\mathrm{T}_{1}$ (15\% pruning) recorded the highest values in all growth stages. The lowest chlorophyll content in Neem leaves was recorded in control. 

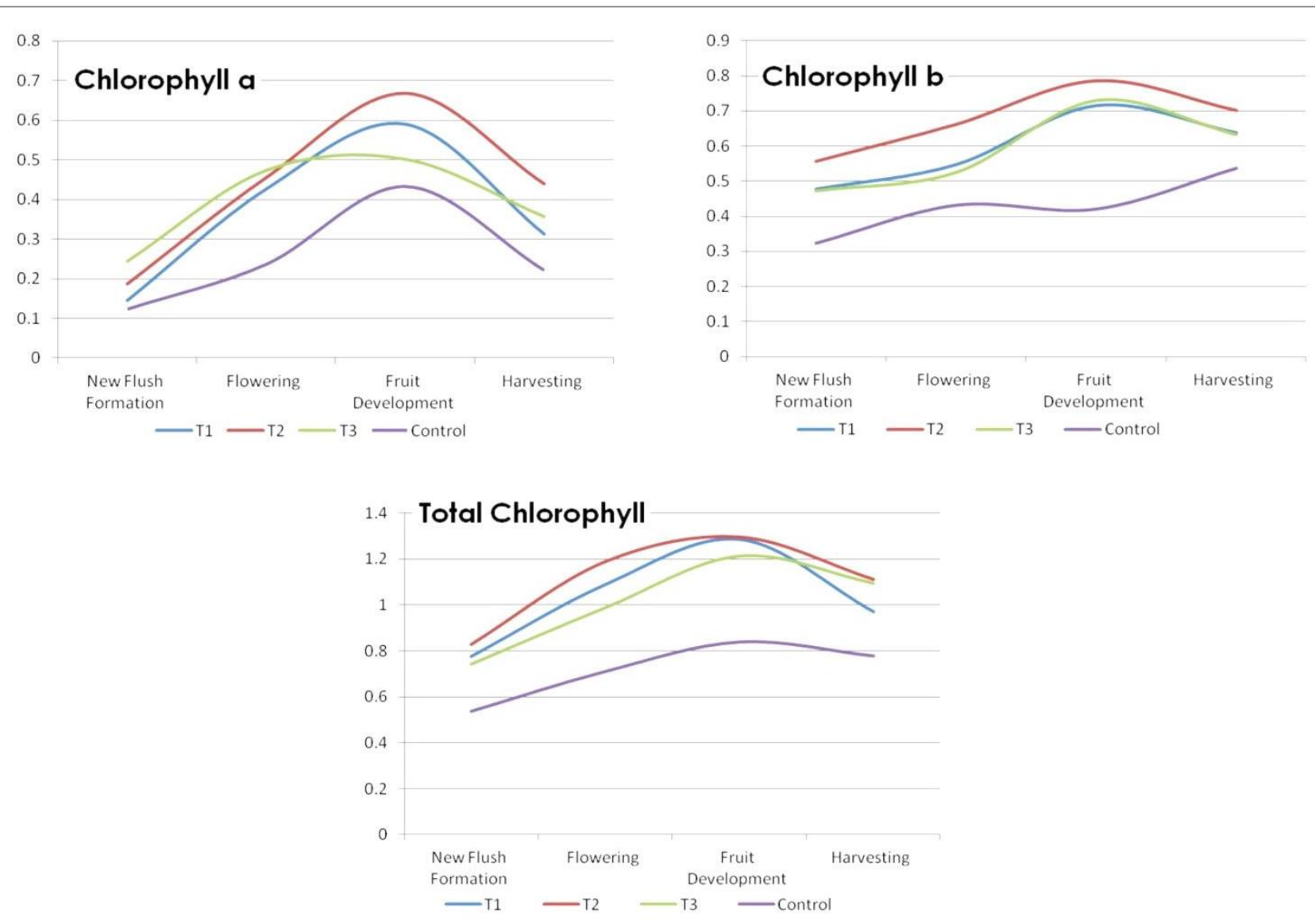

Figure 1. Effect of pruning intensities on chlorophyll content $\left(\mathrm{mg} \mathrm{g}^{-1}\right)$ in Azadirachta indica A. Juss leaves.

\section{Seed yield}

$25 \%$ pruning $\left(\mathrm{T}_{2}\right)$ treatment registered significantly higher seed yield $(3.80 \mathrm{~kg})$ followed by $15 \%$ pruning $(2.79 \mathrm{~kg})$ and control $(1.58 \mathrm{~kg})$ was the least performing treatment, compared to grand mean $(2.66 \mathrm{~kg})$ (Table 5).

Table 5. Effect of different pruning intensities on seed yield of treated Azadirachta indica A. Juss.

\begin{tabular}{|c|c|}
\hline Treatment & Seed yield (kg) \\
\hline $\mathrm{T} 1$ & 2.79 \\
\hline $\mathrm{T} 2$ & $3.80 *$ \\
\hline $\mathrm{T} 3$ & 2.46 \\
\hline $\mathrm{T} 4$ & 1.58 \\
\hline Mean & 2.66 \\
\hline SED & 0.273 \\
\hline CD (0.05) & 0.628 \\
\hline
\end{tabular}

\section{DISCUSSION}

\section{Nutrient status}

When a commercial plantation is grown without silvicultural management practices like pruning of tree then flowering may not be induced (Sivakumar \& Korsten, 2007). The time and position of pruning are essential (Bussi et al., 2010).

The present study indicated that $25 \%$ pruning intensity treatment resulted in maximum amount of leaf nutrient status viz., total nitrogen $(2.351 \%)$, total phosphorus $(0.349 \%)$ and total potassium (2.351) respectively. Hossain \& Fusao (2008) suggested that nutrient status was maximum in pruned trees and minimum at unpruned peach trees. The nutrient status was found to increase from new flush formation to the flowering stage and started to decline from fruit development to harvesting. The leaf potassium content was increased by regular pruning which may induce earliness of the reproductive phase. The untreated trees contained a minimum amount of potassium. From the above findings, unpruned trees were documented with least potassium content compared with other pruning treatments.

\section{Chlorophyll content}

The pruned trees have higher amount of chlorophyll content due to enhancement in the vegetative phase along with the reproductive phase. Much researches on fruit yielding trees revealed that pruning treatment may increase the 
photosynthetic rate via changes in leaf chlorophyll contents (Calatayud et al., 2007).

In the present investigation, $25 \%$ pruning intensity resulted in a higher rate of chlorophyll content in Neem leaves and the lowest was in unpruned trees. The chlorophyll content gradually increased up to the fruit development stage and declined at the harvesting stage. The results revealed that imposing of the different pruning intensities in the Neem trees greatly influenced the chlorophyll content in leaves. These also play a major role in the Neem seed yield. It is also recommended that imposing $25 \%$ and $15 \%$ pruning increases the chlorophyll content.

\section{Seed yield}

Pruning is an essential operation for improvement in seed yield, such it may alter the vegetative phase to the reproductive phase. The large-sized trees, which has wide and dense canopy may prevent light penetration inside the canopy structure and lead to drop the fruit production (Mishra et al., 2011). Among the different pruning intensities, highest seed yield of $3.8 \mathrm{~kg}$ was obtained in $25 \%$ pruning intensity followed by $15 \%(2.79 \mathrm{~kg})$ and the lowest yield of $1.58 \mathrm{~kg}$ in control trees. The results of the present investigation are supported by Prasath et al. (2017) who documented that pruning increased the fruit yield in Tamarindus indica L. at 30\% pruning resulting in maximum fruit yield.

\section{CONCLUSION}

Based on leaf nutrient analysis results was concluded that $T_{2}$ (25\% pruning) and $T_{1}(15 \%$ pruning) were superior in nutrient status and chlorophyll contents at all the four growth stages in Neem plantation. As growth progressed, nutrient status and chlorophyll contents increased from new flush formation stage to the flowering stage and slowly deteriorated from the fruit development stage to the harvesting stage, with significant variation between each pruning treatment. Hence the $25 \%$ pruning intensity is recommended as the optimum pruning intensity is to increase the seed yield of a Neem plantation.

\section{ACKNOWLEDGEMENTS}

This study was carried as part of the collaborative research project between TNAU and Coromandel International Limited, Chennai funded by the Company, which is hereby acknowledged.

\section{REFERENCES}

Bussi C., Francoise L., Vincent M. \& Michel G. (2010). Effects of winter pruning and of water restriction on fruit and vegetative growth, water potential and leaf gas exchange during the final stage of rapid growth in an early maturing peach cultivar. European Journal of Horticultural Science, 75(1): 15-19.

Calatayud A., Roca D., Gorbe E. \& Martynez P.F. (2007). Light acclimation in rose (Rosa hybrida cv. Grand Gala) leaves after pruning: effects on chlorophyll a fluorescence, nitrate reductase, ammonium and carbohydrates. Scientia Horticulture, 111: 152159.

Dhillon W.S. \& Thakur A. (2014). Canopy management and effects of pruning on flowering tendencies in fruit trees. In: National Seminar-cum-Workshop on physiology of flowering in perennial fruit crops. Lucknow, India, pp. 1056-1062.

Prasath C.N.H., Balasubramanian A. \& Radhakrishnan S. (2017). Effect of pruning intensities on leaf nutrient st effect of pruning intensities on leaf nutrient status and fruit yield in and fruit yield in Tamarind plant dharmapuri district of Tamil Nadu, India. Advances in Applied Researches, 1(2): 14-19.

Hossain A.B.M.S. \& Fusao M. (2008). Determination of abscisic acid hormone (ABA), mineral content and distribution pattern of 13C photo assimilates in bark-ringed young peach trees. Maejo International Journal of Science and Technology, 2: $274-284$.

Humphries E.C. (1973). Mineral components and ash analysis. In: Modern methods of Plant Analysis. Springer Verlay Berlin, pp. 468-502.

Jackson M.L. (1973). Soil chemical analysis. Prentice Hall, Inc., Englewood cliffs, N.J. Ed.

Mishra M.U., Wyawahare N.S., Kharwade R. \& Bhongade S.L. (2011). Formulation and evaluation of topical gels of diclofenac using tamarind seed gum. Journal of Pharmacy Research, 4(8): 2622-2624.

Panse V.G. \& Sukhatme P.V. (1978). Statistical methods for agricultural workers New Delhi. ICAR Publication, pp. 41-50.

Piper C.S. (1973). Soil and plant analysis. Hans Published, Bombay, pp. 265.

Sarkka L. \& Erikson C. (2003). Effects of bending and harvesting height combinations on cut rose yield in a dense plantation with high intensity lighting. Scientia Horticulture, 98: 433-447.

Sivakumar D. \& Korsten L. (2007). Relating leaf nutrient status to fruit quality attributes in Litchi cv. 'Mauritius'. Journal of Plant Nutrition, 30: 1727-1735.

Tanee F.B.G. \& Albert E. (2013). Air pollution tolerance indices of plants growing around Umuebulu Gas Flare Station in Rivers State, Nigeria. African Journal of Environmental Science and Technology, 7(1): 1-8.

Yoshida S., Farno D.A., Cock J.H. \& Gomez K.A. (1976). Laboratory manual for physiological studies of Rice. IRRI, Philippines, pp. 70. 